\section{A stable isotope doping method to test the range of applicability of detailed balance}

\section{Z. Liu ${ }^{1,2}$, J.D. Rimstidt ${ }^{3}$, Y. Zhang ${ }^{4}$, H. Yuan ${ }^{5}$, C. Zhu ${ }^{2 *}$}

\section{Abstract}

The principle of detailed balance (PDB) has been a cornerstone for irreversible thermodynamics and chemical kinetics for a long time (Wegscheider, 1901; Lewis, 1925; Onsager 1931), and its wide application in geochemistry has mostly been implicit and without experimental testing of its applicability. Nevertheless, many extrapolations based on PDB without experimental validation have far reaching impacts on society's mega environmental enterprises. Here we report an isotope doping method that independently measures simultaneous dissolution and precipitation rates and can test this principle. The technique reacts a solution enriched in a rare isotope of an element with a solid having natural isotopic abundances (Beck et al, 1992. Gaillardet, 2008; Gruber et al. 2013). Dissolution and precipitation rates 列 that the frulibin We reco equibithe in rate equations for other substances.

Received 25 November 2015 | Accepted 25 January 2016 | Published 15 February 2016

\section{Introduction}

The principle of detailed balance (PDB) arose from statistical and quantum mechanics in the early twentieth century to become a foundation of modern chemical kinetics (Wegscheider, 1901; Lewis, 1925; Onsager, 1931), but its appropriate application to chemical kinetics is obscure because it is difficult to use

1. School of Earth Sciences, Zhejiang University, Hangzhou 300027, China

2. Department of Geological Sciences, Indiana University, Bloomington, IN 47405, USA

* Corresponding author (email: chenzhu@indiana.edu)

3. Doctoral Program in Environmental Science, Indiana University, Bloomington, IN 47405, USA

4. Department of Geosciences, Virginia Tech, Blacksburg, VA 24061, USA

5. State Key Laboratory of Continental Dynamics, Department of Geology, Northwest University, Xian 710069, China

conventional rate experiments to determine independently the forward and reverse rates at equilibrium. As a result, experimental tests of the range of PDB applicability have largely been absent in geochemistry with only a few tests reported in the chemistry, physics, and chemical engineering literature.

The principle states that at equilibrium, the rates of forward and reverse reaction rates are equal (Lasaga, 1998, p.82). When PDB is applicable, the following relationship holds,

$$
K=k_{+} / k_{-}
$$

where $K$ denotes the equilibrium constant, $k_{+}$and $k_{-}$stand for the rate constants for forward and reverse reactions, respectively. Equation 1 is a powerful link between thermodynamics and kinetics (Lasaga, 1998), and a device by which measurements of rate constants for reactions in one direction may be used to obtain the rate constants for the experimentally inaccessible reverse directions (Mahan, 1975). This relies on the assumption that $k_{+}$and $k_{-}$do not change when the reaction departs from equilibrium.

Rimstidt and Barnes (1980) used this principle to obtain both $k_{-}$and $k_{+}$ from quartz dissolution data only. In their widely used kinetic data compilation, Palandri and Kharaka (2004) stated that "Precipitation rate data do not exist fro most minerals...". "Therefore, we use the principle of microscopic reversibility... where the precipitation rate constant can be calculated from the dissolution rate constant and the equilibrium constant."

The most important and far reaching application of PDB in geology is in the so called "transition state theory rate law" or "linear rate law", which expresses mineral dissolution rates as a function of chemical potential (or affinity) (Lasaga, 1981; Aagaard and Helgeson, 1982)

$$
r=S_{A} k\left(1-e^{\frac{\Delta \mu_{r}}{R T}}\right)
$$

where $r$ denotes the net rate of chemical reaction, and $S_{A}$ the surface area. $\Delta \mu_{\mathrm{T}}$ stands for the chemical potential of the reaction, $R$ the gas constant, and $T$ temperature in Kelvin.

Equation 2 assumes that the $K=k_{+} / k_{-}$relationship applies when the reaction is not at equilibrium (see Supplementary Information). Chemists have long known that "rate coefficients determined away from equilibrium are not necessarily the same as those at equilibrium, and their ratio is not necessarily equal to $K_{c}^{\prime \prime}$ (Laidler, 1987, p. 287).

Despite the scepticism expressed by experts and a growing literature describing experiments at near equilibrium that show deviations from this relationship in Equation 2 (see review by Zhu, 2009), this rate law has been widely used in scientific and technological situations, such as the performance models 
for high-level radioactive waste disposal (Grambow, 1985) and geological $\mathrm{CO}_{2}$ sequestration (Johnson et al., 2004; Marini, 2007). The operational periods of these repositories extend beyond 10,000 years and span geochemical conditions far from equilibrium to equilibrium. Failure of the detailed balance assumption would invalidate these important models (see Supplementary Information). Nevertheless, the ad hoc applications continue because of the lack of experimental techniques to test the valid range of extrapolation for the principle of detailed balance.

Here we show that recent advancements in stable isotope analysis by MC-ICP-MS and enriched isotopic standards make it possible to use an isotope doping method to determine the simultaneous dissolution and precipitation rates independently at any degree of saturation so we can validate rate equations and also test the range of applicability of the principle of detailed balance. Although our isotope doping method is applicable to many solid dissolution reactions, we demonstrate it by reacting a saturated $\mathrm{H}_{4}{ }^{29} \mathrm{SiO}_{4}$ aqueous solution with predominantly ${ }^{28} \mathrm{SiO}_{2}$ (quartz).

Quartz makes up about $20 \%$ of the earth's continental crust and there are many implications for its rate of reaction with aqueous solutions. The simultaneous dissolution and precipitation reactions that occur as solids equilibrate with solution are typically modelled using a two-term rate equation. For example, quartz dissolves in water by the reaction

$$
\mathrm{SiO}_{2}(q z)+2 \mathrm{H}_{2} \mathrm{O}(l)=\mathrm{H}_{4} \mathrm{SiO}_{4}(a q)
$$

and the rate of change of silica concentration can be expressed as.

$$
r=k_{+} a_{\mathrm{SiO}_{2}} a_{\mathrm{H}_{2} \mathrm{O}}^{2}-k_{-} a_{\mathrm{H}_{4} \mathrm{SiO}_{4}}=k_{+}-k_{-} a_{\mathrm{H}_{4} \mathrm{SiO}_{4}}
$$

where the activities of $\mathrm{SiO}_{2}$ and $\mathrm{H}_{2} \mathrm{O}$ equal one. The two rate constants cannot be uniquely defined by measuring only the rate of change of elemental silica concentration. This problem is typically circumvented by using the principle of detailed balance to recast the rate equation in terms of one rate constant and the known equilibrium constant $\left(K=k_{+} / k\right)$ (Rimstidt and Barnes, 1980).

$$
r=k_{+}\left(1-{ }_{\mathrm{H}_{4} \mathrm{SiO}_{4}} / \mathrm{K}\right)
$$

However, this approach is valid only if the rate-limiting step (and therefore $k_{+}$ and $k$ ) remains unchanged when the reaction departs from equilibrium. Etch pits (Brantley et al., 1986; Lüttge, 2006) and "leached or re-precipitated layers" (Hellmann et al., 2003), which are not present at equilibrium, suggest that the extrapolation of equilibrium rate constants to highly undersaturated solutions may not be justified. Testing the applicable range for the PDB in cases affected by these and other complications will be difficult. Quartz was chosen for this test of the utility of the isotope doping method because there is good evidence that the PDB is valid over the entire range of undersaturation. Berger et al. (1994) showed that quartz dissolution rates fit Equation 5 and Rimstidt and Barnes (1980) showed that they also fit Equation 4.

\section{Methods}

We tested the validity of Equations 4 and 5 using a stable isotope doping experiment. The silicon in quartz has three stable isotopes and the natural quartz used in our experiments has an isotopic composition of $91.232 \%{ }^{28} \mathrm{Si}, 5.410 \%{ }^{29} \mathrm{Si}$, and $3.3585 \%{ }^{30} \mathrm{Si}$. In our Type 1 equilibrium experiments a solution initially containing nearly $\sim 100 \%{ }^{29} \mathrm{Si}$ was maintained at or near equilibrium with quartz and sampled periodically to find the ${ }^{28} \mathrm{Si}$ and ${ }^{29} \mathrm{Si}$ concentrations. We used the initial rate method (Rimstidt, 2013) to find the rate of appearance of ${ }^{28} \mathrm{Si}$ in solution, which gives the dissolution rate at equilibrium, and the rate of disappearance of ${ }^{29} \mathrm{Si}$, which gives the precipitation rate at equilibrium. The $\mathrm{S}$ isotope abundances in the experimental solutions evolved significantly over the course of experiments but the initial rate method determined the rate at zero time thereby avoiding complications associated with minor but measurable isotopic fractionation.

Two types of experiments were carried out in this study. Type 1 experiments were conducted at equilibrium conditions where the solution was saturated with respect to quartz and Type 2 experiments were performed at far from equilibrium conditions where the initial solution contained no dissolved silica. Type 1 and Type 2 dissolution experiments were both batch reactor experiments conducted at $50 \pm 1{ }^{\circ} \mathrm{C}$. The starting solution for Type 1 experiments contained $340 \mu \mathrm{M}^{29} \mathrm{SiO}_{2}$, which is the solubility of quartz at $50{ }^{\circ} \mathrm{C}$ (Rimstidt, 1997), and the solution was reacted with an ion exchange resin to remove cations that would catalyse the quartz dissolution rate. These solutions remained within $\pm 0.3 \mathrm{~kJ} / \mathrm{mol}$ of equilibrium throughout the experiments. The starting solution for the Type 2 dissolution experiments was deionised water. The $\mathrm{pH}$ of the starting solutions was near 5.5 for both types of experiment. More detailed analytical methods are described in the Supplementary Information section.

\section{Results}

Figure 1 shows the fractional $\mathrm{Si}$ isotope concentrations versus time for the Type 1 equilibrium experiments and Table 1 gives the rates derived from all of the experiments. Figure 2 shows that the dissolution and precipitation rates are essentially the same, thus demonstrating that we have measured the dissolution rate constant at equilibrium. Furthermore, Figure 2 shows that the Type 2 far from equilibrium (no dissolved silica) dissolution rates ( $\mathrm{Q} 2$ experiments) were essentially the same as the equilibrium (saturated solution) rates. The dissolved silica activity in the Type 2 experiments was zero for the initial rate. Inserting that 
value into either Equation 4 or 5 shows that the initial rate equals the dissolution rate constant. This means that the dissolution rate constant $\left(k_{+}\right)$is the same at zero silica concentration as it is at equilibrium.
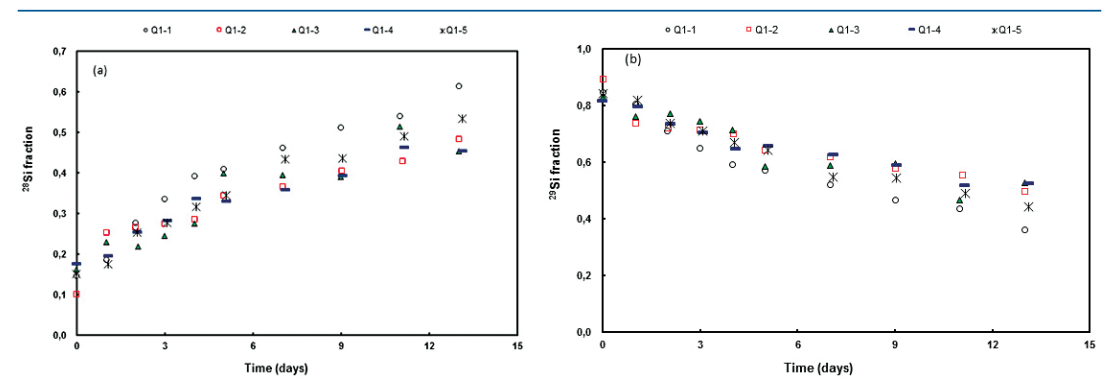
Figure 1 Si isotope fractional abundances in experimental solutions over time. The solution
was saturated with quartz and doped with nearly $100 \%{ }^{29} \mathrm{Si}$. The first sample was taken after 15 minutes. The increase of $28 \mathrm{Si}$ concentration (fractional abundance times dissolved elemental $\mathrm{Si}$ concentration) is due to the dissolution of quartz while the decrease of $29 \mathrm{Si}$ abundances and concentrations is due to the precipitation of quartz. The reaction rates given in Table are based on the slopes of the trends extrapolated to zero time.

Table 1 Rate of quartz dissolution and precipitation at equilibrium based on the rate of Table 1 Rate $28 \mathrm{Si}$ and disappearance of $29 \mathrm{Si}$ respectively, and the far from equilibrium dissolution rate for solutions containing no dissolved silica.

\begin{tabular}{|c|c|c|}
\hline \multirow{2}{*}{ Experiment } & Dissolution rate & Precipitation rate \\
\hline & $\mathrm{mol} / \mathrm{m}^{2} / \mathrm{sec}$ & $\mathrm{mol} / \mathrm{m}^{2} / \mathrm{sec}$ \\
\hline \multicolumn{3}{|c|}{ Type 1 Equilibrium experiments } \\
\hline $\begin{array}{l}\text { Q1-1 } \\
\text { Q1-2 } \\
\text { Q1-3 } \\
\text { Q1-4 } \\
\text { Q1-5 } \\
\text { Average } \\
\text { 土std dev }\end{array}$ & $\begin{array}{r}7.05 \times 10^{-13} \\
6.83 \times 10^{-13} \\
7.65 \times 10^{-13} \\
3.95 \times 10^{-13} \\
6.12 \times 10^{-13} \\
6.32 \times 10^{-13} \\
\pm 1.43 \times 10^{-13}\end{array}$ & $\begin{array}{c}8.40 \times 10^{-13} \\
7.75 \times 10^{-13} \\
9.39 \times 10^{-13} \\
5.64 \times 10^{-13} \\
7.51 \times 10^{-13} \\
7.74 \times 10^{-13} \\
\pm 1.38 \times 10^{-13}\end{array}$ \\
\hline \multicolumn{3}{|c|}{ Type 2 Far from equilibrium experiments } \\
\hline $\begin{array}{l}\text { Q2-1 } \\
\text { Q2-2 } \\
\text { Q2-3 } \\
\text { Q2-4 } \\
\text { Q2-5 } \\
\text { Average } \\
\text { 土std dev }\end{array}$ & $\begin{array}{r}8.32 \times 10^{-13} \\
6.11 \times 10^{-13} \\
6.33 \times 10^{-13} \\
6.66 \times 10^{-13} \\
6.92 \times 10^{-13} \\
6.87 \times 10^{-13} \\
\pm 0.88 \times 10^{-13}\end{array}$ & \\
\hline
\end{tabular}

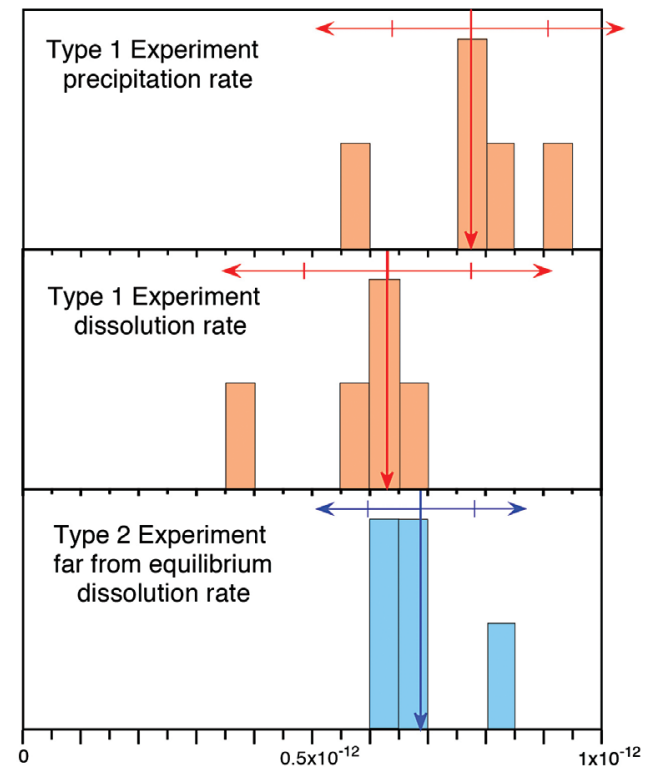

rate, $\mathrm{mol} / \mathrm{m}^{2} / \mathrm{sec}$

Figure 2 Comparison of the equilibrium dissolution and precipitation rates determined using ${ }^{29} \mathrm{Si}$ isotope doping (Type 1 Experiment) with the far from equilibrium dissolution rate (Type Experiment). The vertical arrow points to the average value for each set of experiments and the horizontal arrows indicate two standard deviations of the data.

\section{Discussion and Conclusions}

Our results show that $k_{+}$at zero silica concentration is the same as at equilibrium so we conclude that the $k_{+}$determined at equilibrium is valid at all degrees of undersaturation. This has important implications for predicting rates over a wide range of conditions as explained by Schott et al. (2009).

Another application of our experimental results is the validation of equilibrium constants for quartz solubility. Rimstidt (1997) measured quartz solubility at $25,50,75$, and $96{ }^{\circ} \mathrm{C}$ in experiments up to 4917 days. These long-term experimental data formed the basis for establishing quartz solubility as a function of temperature, and also for deriving the standard thermodynamic properties for aqueous species $\mathrm{H}_{4} \mathrm{SiO}_{4}(\mathrm{aq})$ (Rimstidt, 1997; Stefansson, 2001). However, all experiments approached the quartz solubility from undersaturation and the reverse experiments - precipitation from oversaturation is far more complicated experimentally. Applying Equation 1, we found that the $\log K$ value for reaction (3) at $50{ }^{\circ} \mathrm{C}$ in pure water is -3.50 , which is within the experimental uncertainties in Rimstidt (1997). 
Applying our isotope doping method to quartz reaction rates and solubility is an obvious first step, and the results are confirmatory rather than contradictory to experimental data from conventional methods, which give us confidence to apply the ${ }^{29} \mathrm{Si}$ method used in this study to investigate reactions of the other silicate minerals. Experiments for multicomponent silicate minerals often involve changes of reaction schemes in response to departure from equilibrium (Beig and Lüttge, 2006), and a poorly understood "leached" or "re-precipitated" layer can be developed (Hellmann et al., 2003). Aluminium may inhibit dissolution (Oelkers et al., 1994), and other non-equilibrium surface features may occur so that the far from equilibrium dissolution and precipitation reaction paths can involve different pathways. However, Zhu et al. (2014) showed that this method was promising to measure albite dissolution rates very close to equilibrium, and the interferences of secondary phase precipitation and isotope fractionation was negligible. Detailed investigation of these multicomponent silicate minerals that make up the majority of Earth's crust is the logical next step.

In theory, our isotope doping method can be applied to many solids to test the range of validity of the near equilibrium rate constants. ICP-MS technology eases the analytical problems associated with using this experimental design for a wide range of non-silicate minerals and solids using the increasing number of non-traditional stable isotopes (such as $\mathrm{Mg}$, Fe, Li). Therefore, the application of this method is not limited to geochemistry, but can be used in chemistry, chemical engineering, and environmental sciences as well.

The utility of the principle of detailed balance does not only rest on predicting rate constants or equilibrium constants. Lasaga (1981) gives examples of predicting rate laws, the Arrhenius pre-exponential constants, and activation energy. Our experiments on quartz show the potential for harnessing the power of PDB for obtaining more kinetic parameters in geochemistry. Equally important is that the legitimacy of the extrapolation of PDB rate constants now can be experimentally tested for reactions where the PDB extrapolation has been used to model geological and environmental processes without due reckoning of its applicability.

\section{Acknowledgements}

All experiments were carried out at Indiana University, USA with exception of Si isotope analysis which was carried out at State Key Laboratory of Continenta Dynamics at Northwest University in China. Financial support of this research was provided by the U.S. NSF grant EAR-1225733, and operational funds at the State Key Laboratory of Continental Dynamics. ZYL was supported by funds from Zhejiang University through their "985" project. We thank Eric Oelkers and two anonymous reviewers for their helpful suggestions.

Editor: Eric H. Oelkers

\section{Author Contributions}

JDR and CZ developed the concept, designed the study, interpreted the data and wrote the manuscript. ZYL carried out the experiments, YLZ participated in the interpretation of the data, and HLY developed method and performed the Si isotope analysis.

\section{Additional Information}

Supplementary Information accompanies this letter at www.geochemicalperspectivesletters.org/article1608

Reprints and permission information is available online at http://www geochemicalperspectivesletters.org/copyright-and-permissions

Cite this letter as: Liu, Z., Rimstidt, J.D., Zhang, Y., Yuan, H., Zhu, C. (2016) A stable isotope doping method to test the range of applicability of detailed balance. Geochem. Persp. Let. 2, 78-86.

\section{References}

AaGAARD, P., HelGeSON, H.C. (1982) Thermodynamic and kinetic constraints on reaction rates among minerals and aqueous solutions. I. Theoretical considerations. American Journal of Science 282, 237-285.

BECK, J.W., BERNDT, M.E., SEYFRIED JR, W.E. (1992) Application of isotopic doping techniques to evaluation of reaction kinetics and fluid/mineral distribution coefficients: An experimental study of calcite at elevated temperatures and pressures. Chemical Geology 97, 125-144.

BEIG, M.S., LÜTTGE, A. (2006) Albite dissolution kinetics as a function of distance from equilibrium: Implications for natural feldspar weathering. Geochimica et Cosmochimica Acta 70, 1402-1420.

Berger, G., CAdore, E., Schott, J., Dove, P.M. (1994) Dissolution rate of quartz in lead and sodium electrolyte solutions between 25 and $300^{\circ} \mathrm{C}$ : Effect of the nature of surface complexes and reaction affinity. Geochimica et Cosmochimica Acta 58, 541-551.

Brantley, S.L, Crane, S.R, Crerar, D.A, Hellmann, R, Stallard, R. (1986) Dissolution at dislocation etch pits in quartz. Geochimica et Cosmochimica Acta 50, 2349-2361.

GAILLARDET, J. (2008) Isotope geochemistry as a tool for deciphering kinetics of water-rock interaction, in: Brantley, S.L., Kubicki, J.D., White, A.F. (Eds.) Kinetics of Water-Rock Interaction. Springer New York.

GRAMBOW, B. (1985) A general rate equation for nuclear waste glass corrosion. Materials Reserch Society Symposium Proceedings 44, 15-27.

Gruber, C., Harpaz, L., Zhu, C., Bullen, T.D., GanOR, J. (2013) A new approach for measuring dissolution rates of silicate minerals by using silicon isotopes. Geochimica et Cosmochimica Acta $104,261-280$

Hellmann, R., Penisson, J.-M., Hervig, R.L., Thomassin, J.-H., AbriouX, M.-F. (2003) An EFTEM/HRTEM high-resolution study of the near surface of labradorite feldspar altered at acid pH: evidence for interfacial dissolution-reprecipitation. Physics and Chemistry of Minerals 
JOHNSON, J.W., NitAO, J.J., KNAUSS, K.G. (2004) Reactive transport modeling of $\mathrm{CO}_{2}$ storage in saline aquifers to elucidate fundamental processes, trapping mechanisms and sequestration

LaidLeR, K.J. (1987) Chemical Kinetics. Third Edition, Prentice Hall, New York.

LASAGA, A.C. (1981) Rate laws of chemical reactions. In: Lasaga, A.C., Kirkpatrick, R.J. (Eds.) Kinetics of Geochemical Processes. Mineralogical Society of America, Washington DC, 1-68.

LASAGA, A.C. (1998) Kinetic Theory in the Earth Sciences. Princeton University Press, New York.

LEWIS, G.N. (1925) A new principle of equilibrium. Proceedings of the National Academy of Sciences of the United States of America 11, 179-183.

LÜTTGE, A. (2006) Crystal dissolution kinetics and Gibbs free energy. Journal of Electron Spectroscopy and Related Phenomena 150, 248-259.

MAHAN, B.H. (1975) Microscopic reversibility and detailed balance - analysis. Journal of Chemical Education 52, 299-302

MARINI, L. (2007) Geological Sequestration of Carbon Dioxide. Elsevier, Amsterdam.

OelKeRs, E.H., SCHOTT, J., DevidAL, J.L. (1994) The effect of aluminum, pH, and chemical affinity on the rates of aluminosilicate dissolution reactions. Geochimica et Cosmochimica Acta 58 2011-2024

ONSAGER, L. (1931) Reciprocal relations in irreversible processes. I. Physical Review 37, 405-426.

PALANDRI, J.L., KHARAKA, Y.K. (2004) A compilation of rate parameters of water-mineral interaction kinetics for application to geochemical modeling., U.S. Geological Survey Open File Report 2004-1068, 66.

RIMSTIDT, J.D. (1997) Quartz solubility at low temperatures. Geochimica et Cosmochimica Acta 61 , 2553-2558.

RIMSTIDT, J.D. (2013) Geochemical rate models: An introduction to geochemical kinetics. Cambridge University Press.

RIMSTIDT, J.D., BARNES, H.L. (1980) The kinetics of silica-water reactions. Geochimica et Cosmochimica Acta 44, 1683-1699.

SCHOTT, J., POKROVSKY, O.S., OELKERS, E.H. (2009) The link between mineral dissolution/precipitation kinetics and solution chemistry. Reviews in Mineralogy \& Geochemistry 70, 207-258.

STEFANSSON, A. (2001) Dissolution of primary minerals of basalt in natural waters - I. Calculation of mineral solubilities from 0 degrees C to 350 degrees C. Chemical Geology 172, 225-250.

WegsCHeIDER, R. (1901) Über simultane Gleichgewichte und die Beziehungen zwischen Thermodynamik und Reactionskinetik homogener Systeme. Monatshefte für Chemie / Chemical Monthly 32, 849-906.

ZHU, C. (2009) Geochemical modeling of reaction paths and geochemical reaction networks. Reviews in Mineralogy \& Geochemistry 70, 533-569.

Zhu, C., LiU, Z., Schaefera, A., Wang, C., Zhang, G., Gruber, C., Ganor, J., Georg, R.B. (2014) Silicon isotopes as a new method of measuring silicate mineral reaction rates at ambien temperature. Procedia of Earth and Planetary Sciences 10, 189-193. 